\title{
Caveolin-1 is involved in reactive oxygen species-induced SHP-2 activation in astrocytes
}

\author{
Ji Hee Yun ${ }^{1,2 *}$, Soo Jung Park ${ }^{3,4 *}$, Ara Jo ${ }^{1,2}$, \\ Jihee Lee Kang ${ }^{1,2,6}$, Ilo Jou, ${ }^{3,4}$, \\ Jung Soo Park ${ }^{5}$ and Youn-Hee Choi ${ }^{1,6}$ \\ ${ }^{1}$ Department of Physiology \\ ${ }^{2}$ Tissue Injury Defense Research Center \\ Ewha Womans University School of Medicine \\ Seoul 158-710, Korea \\ ${ }^{3}$ Department of Pharmacology \\ ${ }^{4}$ Chronic Inflammatory Disease Research Center \\ Ajou University School of Medicine \\ Suwon 442-721, Korea \\ ${ }^{5}$ Department of Biochemistry \\ College of Medicine \\ Dankook University \\ Cheonan 330-714, Korea \\ ${ }^{6}$ Corresponding authors: Tel, 82-2-2650-5838; \\ Fax, 82-2-2650-5717; E-mail, yc@ewha.ac.kr (Y.H.C.) \\ Tel, 82-2-2650-5719; Fax, 82-2-2650-5717; \\ E-mail, jihee@ewha.ac.kr (J.L.K.) \\ *These authors contributed equally to this work. \\ http://dx.doi.org/10.3858/emm.2011.43.12.075
}

Accepted 15 September 2011

Available Online 15 September 2011

Abbreviations: Csk, carboxyl-terminal Src kinase; GFAP, glial fibrillary acidic protein; Iba-1, calcium-binding adaptor molecule 1; PTPs, protein-tyrosine phosphatases; ROS, reactive oxygen species; RT, room temperature; SHP-2, src homology 2 domain-containing protein-tyrosine phosphatase 2; siRNA, small interfering RNA; TBS, tris-buffered saline

\begin{abstract}
Recent evidence supports a neuroprotective role of Src homology 2-containing protein tyrosine phosphatase 2 (SHP-2) against ischemic brain injury. However, the molecular mechanisms of SHP-2 activation and those governing how SHP-2 exerts its function under oxidative stress conditions are not well understood. Recently we have reported that reactive oxygen species (ROS)-mediated oxidative stress promotes the phosphorylation of endogenous SHP-2 through lipid rafts, and that this phosphorylation strongly occurs in astrocytes, but not in microglia. To investigate the molecules involved in events leading to phosphorylation of SHP-2, raft proteins were analyzed using astrocytes
\end{abstract}

and microglia. Interestingly, caveolin-1 and -2 were detected only in astrocytes but not in microglia, whereas flotillin-1 was expressed in both cell types. To examine whether the $\mathrm{H}_{2} \mathrm{O}_{2}$-dependent phosphorylation of SHP-2 is mediated by caveolin-1, we used specific small interfering RNA (siRNA) to downregulate caveolin-1 expression. In the presence of caveolin-1 siRNA, the level of SHP-2 phosphorylation induced by $\mathrm{H}_{2} \mathrm{O}_{2}$ was significantly decreased, compared with in the presence of control siRNA. Overexpression of caveolin-1 effectively increased $\mathrm{H}_{2} \mathrm{O}_{2}$-induced SHP-2 phosphorylation in microglia. Lastly, $\mathrm{H}_{2} \mathrm{O}_{2}$ induced extracellular signal-regulated kinase (ERK) activation in astrocytes through caveolin-1. Our results suggest that caveolin-1 is involved in astrocyte-specific intracellular responses linked to the SHP-2-mediated signaling cascade following ROS-induced oxidative stress.

Keywords: astrocytes; caveolin-1; microglia; protein tyrosine phosphatase, non-receptor type 11; reactive oxygen species

\section{Introduction}

Src homology 2-containing protein tyrosine phosphatase 2 (SHP-2), a member of a subfamily of protein tyrosine phosphatases (PTPs), is highly expressed in specific regions of the rat brain, including the cortex, cerebellum, and hippocampus (Suzuki et al., 1995). Earlier studies show that SHP-2 is involved in neuroprotection in response to ischemic brain injury (Aoki et al., 2000; Chong et al., 2003; Gee and Mansuy, 2005). Overexpression of a catalytically inactive mutant of SHP-2 increases susceptibility to focal cerebral ischemia/reperfusion injury in the mouse adult brain (Aoki et al., 2000). Moreover, SHP-2 inhibition leads to reduced survival and increased programmed cell death of primary cultured neurons during nitric oxide exposure (Chong et al., 2003). However, the molecular mechanisms of SHP-2 activation and those governing how SHP-2 exerts its function under oxidative stress conditions are not well understood at present.

Recent studies in our laboratory have suggested that $\mathrm{H}_{2} \mathrm{O}_{2}$-mediated oxidative stress induces SHP-2 phosphorylation and activation through lipid rafts, 
A

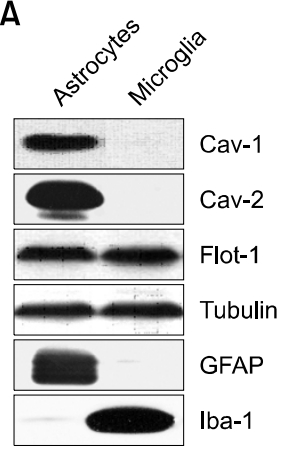

B

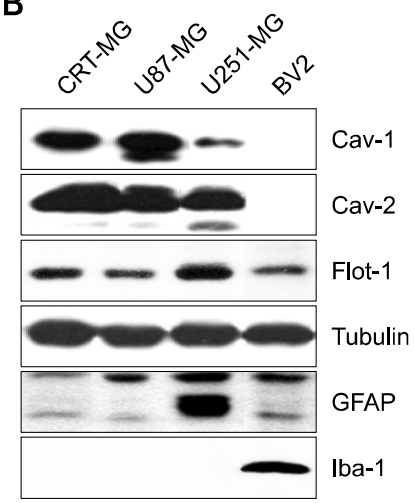

Figure 1. Differential expression of caveolins of astrocytes and microglia. (A) Cell lysates $(25 \mathrm{mg})$ obtained from rat primary astrocytes and microglia were analyzed by immunoblotting using antibodies against caveolin-1 (Cav-1), caveolin-2 (Cav-2), and flotillin-1 (Flot-1). (B) Cell lysates $(25 \mathrm{mg})$ from human astroglioma cell lines (CRT-MG, U87-MG, and U251-MG) and BV2 mouse microglia were subjected to immunoblotting as in (A). Tubulin was used as a loading control. The cell-type specific markers, GFAP and Iba-1, were utilized to identify astrocytes and microglia, respectively. The experiment was repeated at least 3 times, with similar results.

since we found that $\mathrm{H}_{2} \mathrm{O}_{2}$-mediated SHP-2 phosphorylation was inhibited by lipid raft-disrupting agents such as filipin III and methyl- $\beta$-cyclodextrin (Park et al., 2009). There are 2 common raft domains in mammalian cells: planar lipid rafts and caveolae (Allen et al., 2007). Caveolins are a major component and marker of caveolae and flotillin is analogous, but not homologous, to caveolin in planar lipid rafts. Caveolin-1, a 21-24 kDa membrane protein which is associated with cell surface caveolae, is a multifunctional scaffolding protein and serves as a modulator of cell signaling by directly interacting with signaling molecules. Caveolin-1 and caveolae have been implicated in diverse cellular processes such as vesicular transport, cell migration, cell cycle regulation, cell proliferation, cell transformation, and signal transduction (Williams and Lisanti, 2005; Kim et al., 2010). Caveolin-2 and caveolin-3, 2 other proteins of the same family, are expressed differently in various cell types. In the brain, caveolins are widely expressed in astrocytes, endothelial cells, oligodendrocytes, Schwann cells, dorsal root ganglia, and hippocampal neurons (Cameron et al., 1997). In contrast, most neurons are known to contain planar lipid rafts (non-caveolar rafts) and flotillin, but not caveolae and caveolins (Lang et al., 1998). However, the roles of caveolin-1 and flotillin in the brain are still unclear.

The effect of $\mathrm{H}_{2} \mathrm{O}_{2}$ on SHP-2 phosphorylation appears to be cell-type specific; we previously found that phosphorylation was strongly induced

by $\mathrm{H}_{2} \mathrm{O}_{2}$ in rat primary astrocytes, but barely detectable in microglia. The goal of the present study is to elucidate the means by which SHP-2 phosphorylation and modification occurs, specifically in astrocytes in the presence of $\mathrm{H}_{2} \mathrm{O}_{2}$. In this study, we examined the expression pattern of raft proteins, in astrocytes and microglia, and showed for the first time that caveolin-1 and -2 are expressed particularly in astrocytes and that the presence of caveolin-1 in astrocytes contributes to enhanced SHP-2/ERK signaling in response to $\mathrm{H}_{2} \mathrm{O}_{2}$.

\section{Results}

\section{Differential expression of caveolin-1 and -2 in astrocytes and microglia}

We initially examined the expression pattern of raft proteins such as caveolin and flotillin in rat primary astrocytes and microglia. Primary cells were cultured as described in the Materials and Methods section, and cultures were confirmed as being enriched with astrocytes and microglia by immunoblotting with anti-glial fibrillary acidic protein (GFAP) and anti-ionized calcium-binding adaptor molecule 1 (Iba-1) antibodies, markers for astrocytes and microglia, respectively. Interestingly, caveolin-1 and -2 were detected only in astrocytes but not in microglia, whereas flotillin-1 was expressed in both types of cell (Figure 1A). To examine the expression pattern of caveolins in astrocytes, we next screened several astroglioma cell lines such as CRT-MG, U87-MG, and U251-MG, and the microglia cell line, BV2. The expression pattern of caveolins and flotillin in a number of cell lines was similar to that of primary cells; caveolin- 1 and -2 were detected only in astroglioma cell lines, although the expression level was different, whereas flotillin-1 was found in all cell lines studied (Figure 1B). The expression level of GFAP was different; a high level of GFAP protein was observed in U251-MG cells, while U87-MG and CRT-MG cells expressed low levels, in keeping with previous results (Godbout et al., 1998).

\section{SHP-2 phosphorylation is strongly induced by $\mathrm{H}_{2} \mathrm{O}_{2}$ in rat primary astrocytes and human astroglioma cells but barely detectable in microglia}

Recently we reported that reactive oxygen species (ROS)-mediated oxidative stress promotes the phosphorylation of endogenous SHP-2 through lipid rafts in astrocytes, but not in microglia (Park et al., 2009). The SHP-2 phosphorylation level 
mediated by $\mathrm{H}_{2} \mathrm{O}_{2}$ was significantly higher in astrocytes than in microglia, although the protein was abundantly expressed in both cell types (Figure 2A), similarly to our previous report. To determine whether $\mathrm{H}_{2} \mathrm{O}_{2}$-induced phosphorylation of SHP-2 is a common occurrence in other cell lines, we performed similar experiments with astroglioma and microglia cell lines. The pattern of SHP-2 phosphorylation was similar to that of primary cells (Figure 2B).

\section{$\mathrm{H}_{2} \mathrm{O}_{2}$-induced SHP-2 phosphorylation is affected by caveolin-1}

Because caveolin-1 expression was undetectable in BV-2 microglia cells, we overexpressed caveolin-1 using an adenoviral system. Interestingly, adenovirusmediated transduction of caveolin-1 in BV2 cells increased $\mathrm{H}_{2} \mathrm{O}_{2}$-induced SHP-2 phosphorylation (Figure 3A). Total lysates from adenovirus-infected BV2 cells were blotted with $4 \mathrm{G} 10$ antibody to show the cell activation status. $\mathrm{H}_{2} \mathrm{O}_{2}$ induced the tyrosine phosphorylation of several proteins in adenovirus mock-infected BV2 cells (Figure 3B, lane 2), and this phosphorylation was strongly enhanced in adenovirus-caveolin-1-infected BV2 cells even at the same concentration of $\mathrm{H}_{2} \mathrm{O}_{2}$ (Figure $3 \mathrm{~B}$, lane 4). Next, we tested whether the downregulation of caveolin-1 expression using specific small interfering

A
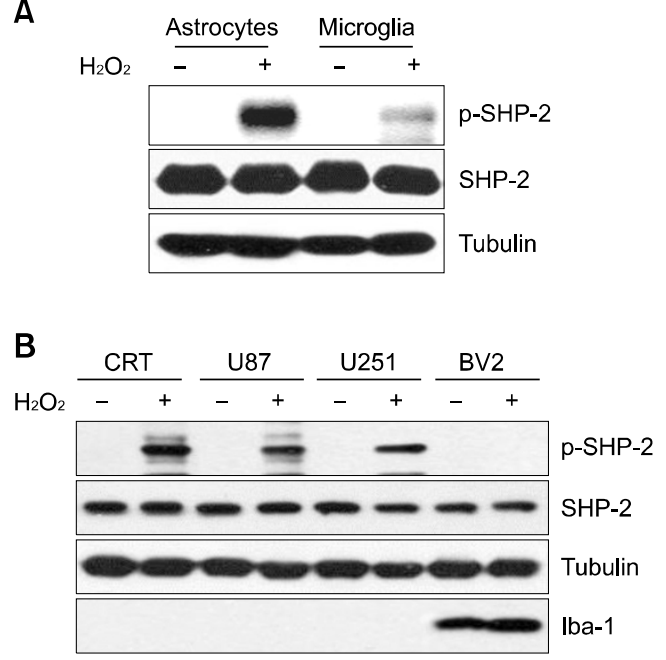

Figure 2. SHP-2 phosphorylation is strongly induced by $\mathrm{H}_{2} \mathrm{O}_{2}$ in rat astrocytes and in human astroglioma cells, but not in microglia. (A) Rat primary astrocytes and microglia were treated with $1 \mathrm{mM} \mathrm{H}_{2} \mathrm{O}_{2}$ for $10 \mathrm{~min}$, and cells were then lysed and analyzed by immunoblotting, probing with antibodies against SHP-2 and phospho-SHP-2. (B) Cell lysates obtained from human astroglioma cell lines and BV2 mouse microglia, which were treated with 0-1 $\mathrm{mM} \mathrm{H}_{2} \mathrm{O}_{2}$ for 10 min, were subjected to immunoblotting with the p-SHP-2/SHP-2 antibodies. Antibodies to tubulin and Iba-1 were used as a loading control and as a microglia-specific marker, respectively. Data are representative of at least 3 experiments. p, phospho.
RNA (siRNA) affects $\mathrm{H}_{2} \mathrm{O}_{2}$-induced SHP-2 phosphorylation in astrocytes. Transfection of astrocytes with caveolin-1 siRNA decreased endogenous caveolin-1 expression. In the presence of caveolin-1 siRNA, the level of SHP-2 phosphorylation induced by $\mathrm{H}_{2} \mathrm{O}_{2}$ in rat primary astrocytes was significantly decreased compared with that in cells treated with control siRNA (Figure 4A) and in CRT-MG human astroglioma cells (Figure 4B). These results indicate that the presence of caveolin-1 affects the extent of SHP-2 phosphorylation in the presence of $\mathrm{H}_{2} \mathrm{O}_{2}$.

\section{$\mathrm{H}_{2} \mathrm{O}_{2}$ induces caveolin-1-SHP-2 complex formation}

SHP-2 is primarily present in the cytosol, but this enzyme is recruited to its target molecules in lipid rafts to act as either a positive or negative regulator in several signaling pathways (Pluskota et al., 2000; Lacalle et al., 2002; Kim et al., 2006). To test whether SHP-2 interacts with caveolin-1, co-immunoprecipitation was performed in CRT-MG astroglioma cells either in the absence or presence of $\mathrm{H}_{2} \mathrm{O}_{2}$. As shown in Figure $5 \mathrm{~A}$, complex formation occurred between caveolin-1 and SHP-2 following $\mathrm{H}_{2} \mathrm{O}_{2}$ treatment of CRT-MG cells, and this was enhanced by caveolin-1 overexpression through adenovirus-mediated transduction. Reverse immunoprecipitation using anti-caveolin-1 antibody was employed in primary astrocytes and this also demonstrated the association between caveolin-1

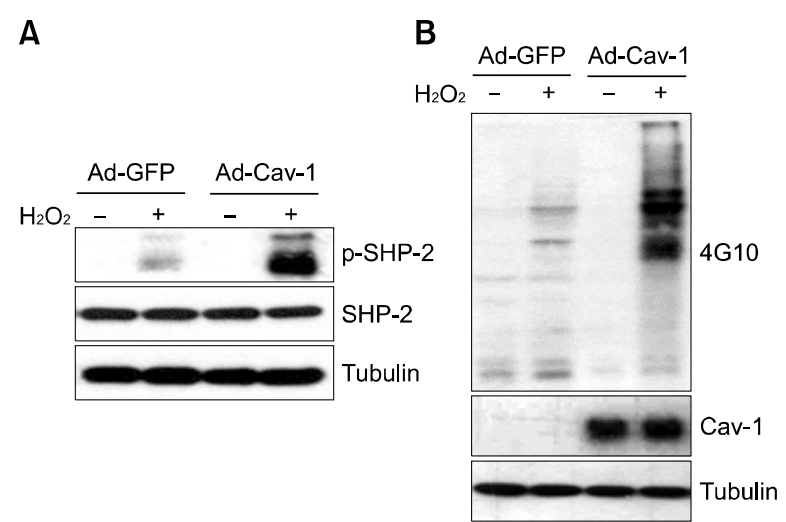

Figure 3. Infection of Ad-caveolin-1 increases $\mathrm{H}_{2} \mathrm{O}_{2}$-induced SHP-2 phosphorylation in BV2 microglia. (A) BV2 microglia transduced with either recombinant adenovirus carrying caveolin-1 (Ad-cav-1) or control virus (Ad-GFP) for $48 \mathrm{~h}$ were treated with $5 \mathrm{mM} \mathrm{H}_{2} \mathrm{O}_{2}$ for $10 \mathrm{~min}$, and the cell lysates were subjected to immunoblotting with anti-SHP-2, anti-p-SHP-2 and anti-tubulin antibodies. (B) Whole cell lysates from BV2 cells transduced with either Ad-cav-1 or Ad-GFP in the presence or absence of $\mathrm{H}_{2} \mathrm{O}_{2}$ were analyzed using the $4 \mathrm{G} 10$ antibody. Effective adenovirus-mediated transduction of caveolin-1 was verified by immunoblotting against caveolin-1 protein expression for each assay. Data shown are representative of at least 3 experiments. p, phospho. 
A

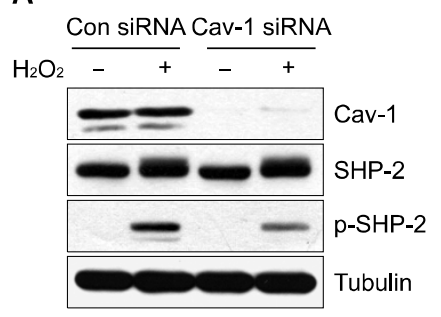

B

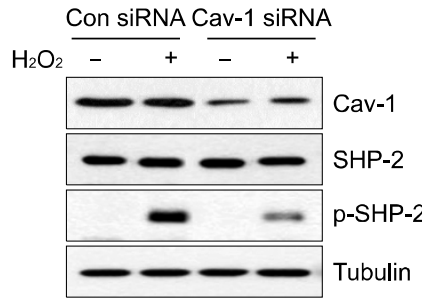

Figure 4. Caveolin-1 knockdown by small interfering RNA reduces $\mathrm{H}_{2} \mathrm{O}_{2}$-induced SHP-2 phosphorylation in rat primary astrocytes and in CRT-MG human astroglioma cells. Rat primary astrocytes (A) and human astroglioma CRT-MG cells (B) were transfected with caveolin-1 siRNA (Cav-1 siRNA) or scrambled siRNA (Con siRNA). Two days after transfection, cells were incubated with $1 \mathrm{mM} \mathrm{H} \mathrm{H}_{2}$ for 10 min or left untreated, lysed, and analyzed by immunoblotting with anti-cav-1, anti-SHP-2, anti-p-SHP-2, and anti-tubulin antibodies. Effective siRNA-mediated suppression of caveolin-1 protein expression was verified for each assay by immunoblotting. The experiment was repeated at least 3 times, with similar results. p, phospho.

and SHP-2; this association was found mainly in the detergent-insoluble fraction (Figure 5B). To clarify whether SHP-2 is located in caveolin-containing lipid-raft fractions in response to $\mathrm{H}_{2} \mathrm{O}_{2}$, a detergentfree, sucrose gradient centrifugation procedure was further utilized. SHP-2 and caveolin-1 were mainly detected in the low-buoyant-density fraction of sucrose gradients, fractions 3 and 4 , upon $\mathrm{H}_{2} \mathrm{O}_{2}$ treatment in primary astrocytes. To analyze SHP-2caveolin-1 colocalization, primary astrocytes were incubated in the absence or presence of $\mathrm{H}_{2} \mathrm{O}_{2}$ for $10 \mathrm{~min}$, fixed, and then stained for total p-SHP-2 (Figure 5C, green) after which they were stained for caveolin-1 (red). The merged images show that caveolin-1 and p-SHP-2 partially co-localize at the plasma membrane in the presence of $\mathrm{H}_{2} \mathrm{O}_{2}$ in astrocytes.

\section{Caveolin-1 is involved in $\mathrm{H}_{2} \mathrm{O}_{2}$-mediated ERK activation in astrocytes}

SHP-2 has been shown to play a positive role in mediating ERK activation by cytokine receptors and receptor tyrosine kinases (Tang et al., 1995; Bennett et al., 1996; Gu et al., 1998; Shi et al., 1998; Kim and Baumann, 1999). The level of

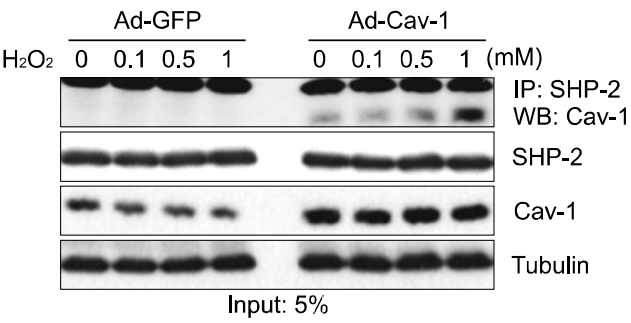

B
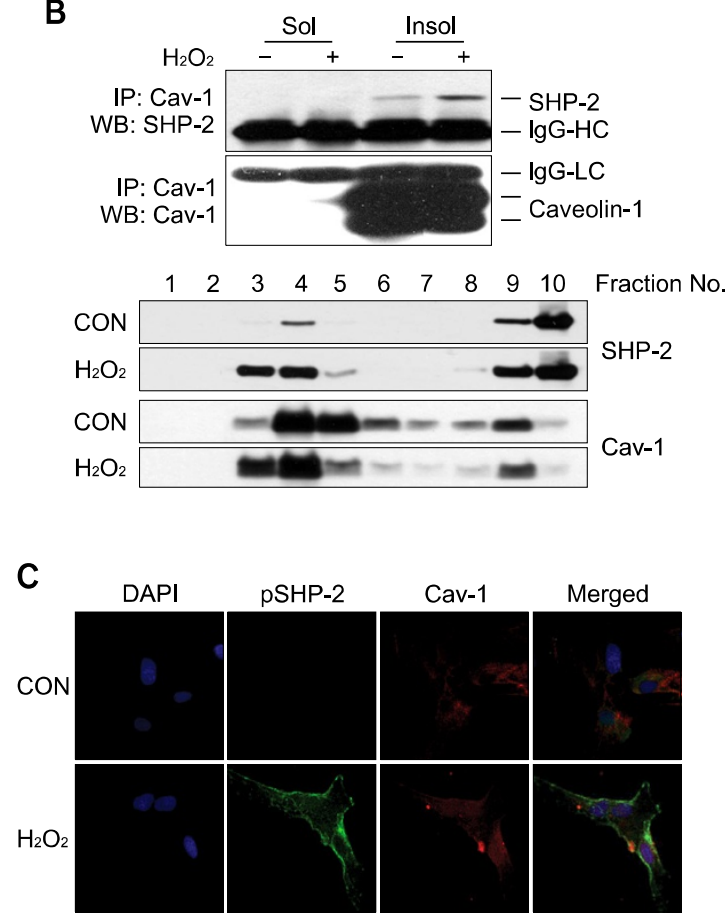

Figure 5. $\mathrm{H}_{2} \mathrm{O}_{2}$ enhances the association of caveolin-1 and SHP-2. (A) The CRT-MG human astroglioma cells transduced with recombinant adenovirus carrying caveolin-1 (Ad-Cav-1) or control virus (Ad-GFP) for 48 $\mathrm{h}$ were treated with $0-1 \mathrm{mM} \mathrm{H}_{2} \mathrm{O}_{2}$ for 10 min as indicated, and cell lysates (500 mg) were extracted and subjected to immunoprecipitation using an anti-SHP-2 antibody. Anti-SHP-2 immunoprecipitates were analyzed by immunoblotting with anti-caveolin-1. Input (5\%) was shown. (B) Rat primary astrocytes were treated with 0-1 $\mathrm{mM} \mathrm{H}_{2} \mathrm{O}_{2}$ for 10 min and fractionated into soluble or insoluble fractions using Brii 58. Both fractions were immunoprecipitated with an anti-caveolin-1 antibody, and analyzed by immunoblotting using anti-SHP-2 antibody. The same blot was reprobed with an anti-caveolin-1 antibody. For a detergent-free sucrose gradient centrifugation procedure, cells were incubated in the presence or absence of $\mathrm{H}_{2} \mathrm{O}_{2}$ and homogenized. The sucrose concentration was adjusted and the homogenate separated by $5 \% / 35 \%$ discontinuous sucrose gradient centrifugation, as described under Materials and Methods. Each fraction was analyzed by Western blotting using anti-caveolin-1 and anti-SHP-2 antibodies. Data shown are representative of at least 3 experiments. (C) Rat primary astrocytes were treated with $1 \mathrm{mM} \mathrm{H}_{2} \mathrm{O}_{2}$ or left untreated for $10 \mathrm{~min}$, stained with rabbit polyclonal anti-p-SHP-2 and mouse monoclonal anti-caveolin antibody, and analyzed by immunofluorescence microscopy. Nuclei were stained with DAPI. The experiment was repeated at least 3 times, with similar results (original magnification, $\times 400)$. 


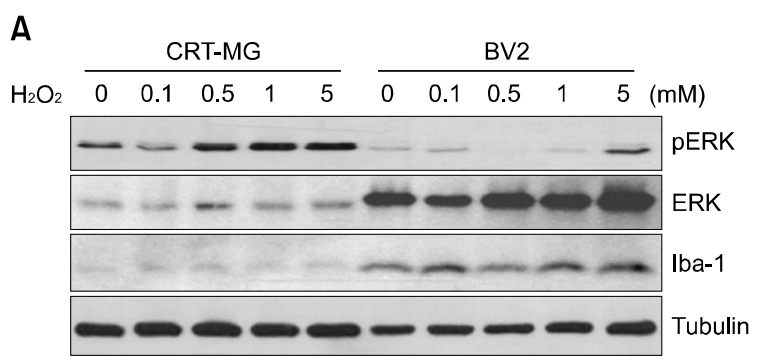

B

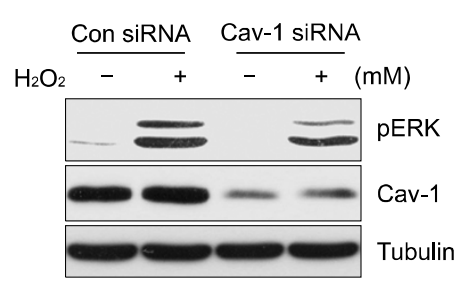

Figure 6. Caveolin-1 is involved in $\mathrm{H}_{2} \mathrm{O}_{2}$-mediated ERK activation in astrocytes. (A) Human astroglioma CRT-MG and BV2 mouse microglia were treated with a range of $\mathrm{H}_{2} \mathrm{O}_{2}$ concentrations $(0-5 \mathrm{mM})$ for $10 \mathrm{~min}$, and analyzed by immunoblotting with anti-p-ERK, anti-ERK, anti-caveolin-1, and anti-tubulin antibodies. Iba-1 was used as a loading control and as a microglia-specific marker. (B) Human astroglioma CRT-MG cells were transfected with human caveolin-1 siRNA (Cav-1 siRNA) or scrambled siRNA (Con siRNA). Two days after transfection, cells were incubated with $1 \mathrm{mM} \mathrm{H}_{2} \mathrm{O}_{2}$ for 10 min or left untreated, lysed, and analyzed by immunoblotting with anti-p-ERK, anti-caveolin-1, and anti-tubulin antibodies. Effective siRNA-mediated suppression of caveolin-1 protein expression was verified for each assay by immunoblotting. The experiment was repeated at least 3 times, with similar results. p, phospho.

phosphorylated ERK was examined in CRT-MG and BV2 cells. ERK phosphorylation levels mediated by $\mathrm{H}_{2} \mathrm{O}_{2}$ were significantly higher in astrocytes than in microglia, although the ERK protein was abundantly expressed in BV2 microglia (Figure 6A). This phosphorylation was induced in a dose-dependent

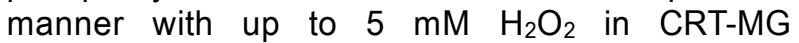
astroglioma cells. Because the transfection of astrocytes with caveolin-1 siRNA decreased the level of SHP-2 phosphorylation induced by $\mathrm{H}_{2} \mathrm{O}_{2}$, we next tested the effect of caveolin-1 on ERK activation. Transfection with caveolin-1 siRNA decreased endogenous caveolin-1 expression in rat primary astrocytes. In the presence of caveolin-1 siRNA, the level of ERK phosphorylation induced by $\mathrm{H}_{2} \mathrm{O}_{2}$ was significantly decreased, compared with that in the presence of control siRNA (Figure $6 B)$.

\section{Discussion}

In an earlier paper, we demonstrated that $\mathrm{H}_{2} \mathrm{O}_{2-}$ mediated oxidative stress strongly induces SHP-2 phosphorylation, particularly in astrocytes, and lipid rats are involved in this events (Park et al., 2009). Since this phosphorylation was barely detectable in microglia, we have explored the means by which SHP-2 phosphorylation and modification occurs specifically in astrocytes, but not in microglia, in the presence of $\mathrm{H}_{2} \mathrm{O}_{2}$. In this study, we examined the differences between astrocytes and microglia in terms of the expression pattern of raft proteins. We showed the different expression level of caveolin-1 and -2 in these cells and also demonstrated that the expression level of caveolin-1 could affect the extent of SHP-2 and ERK phosphorylation in response to $\mathrm{H}_{2} \mathrm{O}_{2}$.

Caveolin-1 is the most studied of the caveolin protein family members and has numerous functions in cellular senescence, transformation, and tumorigenesis through the regulation of signal transduction cascades by recruiting various signaling proteins (Volonte et al., 2002; Cho and Park, 2005; Williams and Lisanti, 2005). This regulation is known to act most commonly in an inhibitory fashion, with release from caveolin-1 enabling activation (Razani et al., 2002). However, positive regulatory functions have also been demonstrated, as are seen in insulin receptor signaling and transforming growth factor-beta (TGF $\beta$ )-induced Rho A activation processes (Yamamoto et al., 1998; Peng et al., 2008). In our studies, $\mathrm{H}_{2} \mathrm{O}_{2}$-mediated SHP-2/ERK phosphorylation was reduced in astrocytes by caveolin-1 siRNA, suggesting that caveolin-1 may function as a positive regulator in SHP-2/ERK signaling pathways in response to $\mathrm{H}_{2} \mathrm{O}_{2}$ in astrocytes.

It has been shown that caveolin-1 acts as docking site to anchor various proteins within caveolae, regulates a variety of signaling molecules, and modulates downstream signaling pathways negatively or positively (Couet et al., 1997; Razani et al., 2002; Gonzalez et al., 2004). Our data demonstrate that caveolin-1 could bind to SHP-2 in the presence of $\mathrm{H}_{2} \mathrm{O}_{2}$. The association of caveolin-1 and carboxyl-terminal Src kinase (Csk) is reported to occur in response to $\mathrm{H}_{2} \mathrm{O}_{2}$ and insulin (Cao et al., $2002,2004)$. Since we and others have shown that caveolin-1 is likely to associate with SHP-2 and Csk, further studies should elucidate whether caveolin-1 binds to these 2 proteins simultaneously, or binds to each of them in a competitive manner, by analyzing the components of the caveolin-1 binding complex. If caveolin-1 binds to each protein in response to $\mathrm{H}_{2} \mathrm{O}_{2}$, further work will also be needed to compare the binding affinity of both SHP-2 and Csk to caveolin-1. It will be interesting to determine whether these 2 proteins function in a coordinated fashion to regulate Src kinase activity 
in astrocytes.

In our system, caveolin-1 was barely detectable in microglia in contrast to astrocytes. Our results demonstrate that astrocytes endogenously expressed a certain level of caveolin-1 and this expression level in astrocytes was sufficient to induce SHP-2 phosphorylation in the presence of $\mathrm{H}_{2} \mathrm{O}_{2}$, while microglia barely expressed caveolin-1 and failed to induce strong SHP-2 phosphorylation even with exposure to the same concentration of $\mathrm{H}_{2} \mathrm{O}_{2}$. Increased expression of caveolin-1 seems to promote protein tyrosine phosphorylation in response to $\mathrm{H}_{2} \mathrm{O}_{2}$. Results from immunoblotting experiments with 4G10 antibody showed that the tyrosine phosphorylation of several proteins was enhanced in caveolin-1-infected BV2 cells (Figure 4B). A similar result was observed in HEK293T cells, which express low levels of caveolin-1 protein, following $\mathrm{H}_{2} \mathrm{O}_{2}$ exposure (Percy et al., 2008). Transduction of caveolin-1 was sufficient to induce significant tyrosine phosphorylation in HEK293T cells upon exposure to $\mathrm{H}_{2} \mathrm{O}_{2}$ (data not shown). Our observation is consistent with the previous study, and these results suggest that the presence of caveolin-1 in these cells enhances intracellular protein tyrosine phosphorylation when cells are exposed to $\mathrm{H}_{2} \mathrm{O}_{2}$.

In this study, we provide evidence of a novel signaling pathway implicating caveolin-1 as a positive regulator of $\mathrm{H}_{2} \mathrm{O}_{2}$-induced SHP-2/ERK signaling in astrocytes. Since we observed that the presence of caveolin-1 and its expression level were critical for the extent of $\mathrm{H}_{2} \mathrm{O}_{2}$-induced SHP-2 phosphorylation, we believe that caveolin-1 is one of the necessary upstream regulators of this event. Our results suggest that astrocytes possess specific intracellular responses linked to the caveolin-1-mediated signaling cascade following $\mathrm{H}_{2} \mathrm{O}_{2}$ treatment, unlike microglia, which express low levels of caveolin-1 protein. Although other intrinsic differences between astrocytes and microglia cannot be ruled out, our study clarifies which SHP-2/ERK phosphorylation occurs specifically in astrocytes (but not in microglia) following $\mathrm{H}_{2} \mathrm{O}_{2}$ exposure, via caveolin-1, and helps to broaden our understanding of the differences between astrocytes and microglia in the context of oxidative stress-mediated signaling pathways.

\section{Methods}

\section{Cells}

Primary astrocytes and microglia from the cerebral cortices of 1-day-old Sprague-Dawley rats were cultured as described previously (Park et al., 2009). Confirmation of astrocyte- and microglia-enriched cultures were assayed by immunostaining utilizing anti-GFAP and anti-lba-1 antibodies, the respective markers for astrocytes and microglia. CRT-MG, U87-MG and U251-MG human astroglioma cells were cultured in DMEM supplemented with $4 \mathrm{mM}$ L-glutamine, $10 \%$ heat-inactivated fetal bovine serum, and $1 \mathrm{mM}$ sodium pyruvate as previously described (Choi et al., 2002). The mouse microglial cell line BV-2 and HEK293 were grown in DMEM supplemented with $4 \mathrm{mM}$ L-glutamine, $10 \%$ heat-inactivated fetal bovine serum, and $1 \mathrm{mM}$ sodium pyruvate (Repovic and Benveniste, 2002).

\section{Reagents}

$\mathrm{H}_{2} \mathrm{O}_{2}$ were purchased from Sigma (St. Louis, MO). Antibody against phospho-SHP-2 was obtained from Cell Signaling (Beverly, MA) and antibodies against SHP-2, caveolin-1, caveolin-2 and flotillin-1 were obtained from BD (Lexington, KY). Anti-caveolin-3, anti-phospho-ERK/ERK antibodies were obtained from Santa Cruz (Santa Cruz, CA). Anti-lba-1 antibody was obtained from Wako Pure Chemical Industries (Osaka, Japan). Anti-GFAP and antitubulin antibodies were obtained from Sigma. Horseradish peroxidase (HRP)-conjugated secondary antibodies for Western blotting were obtained from Santa Cruz Technology.

\section{Transfection of siRNA}

SiRNA against the coding sequence of human caveolin-1 was designed as described previously (Kim et al., 2008). Control siRNA against green fluorescence protein (GFP) was purchased from Samchully Pharm Co. Ltd. (Seoul, Korea). The siRNA sequences were: human caveolin-1 (1) (sense: AACCAGAAGGGACACACAGUU; antisense: AACUGUGUGUCCCUUCUGGUU), and (2) (sense: CCUUCACUGUGACGAAAUATT; antisense: UAUUUCGUCACAGUGAAGGTT) and GFP as control siRNA (sense: GUUCAGCGUGUCCGGCGAGTT; anti-sense: CUCGCCGGACACGCUGAACTT). Transfection of siRNA was performed using Mirus TransIT-TKO ${ }^{\circledR}$ siRNA transfection reagents (Mirus, Madison, $\mathrm{WI}$ ), according to the manufacturer's instructions, to achieve a final RNA concentration of $200 \mathrm{nM}$. Cells were allowed to recover in DMEM with $10 \%$ FBS for $48 \mathrm{~h}$ before treatment with $0-5 \mathrm{mM} \mathrm{H}_{2} \mathrm{O}_{2}$ for 10 min, and analyzed by immunoblotting. Smartpool siRNA against the coding sequence of rat caveolin-1 was purchased from Dharmacon (Dharmacon Research, Lafayette, CO). SiRNA against SHP-2 and non-targeting control siRNA was purchased from Dharmacon. Transfection of siRNA was performed using DharmaFECT siRNA transfection reagents (Dharmacon), according to the manufacturer's instructions, to achieve a final RNA concentration of $200 \mathrm{nM}$.

\section{Adenoviral gene transfer - caveolin-1 expression}

Adenoviral human caveolin-1 were constructed as described previously (Park et al., 2005). The efficiency of infections was monitored by GFP expression and expression of caveolin-1 was confirmed by immunoblotting. The construction of adenoviral vectors was performed as described previously (Park et al., 2005). Briefly, recombinant adenovirus was made by using the AdEasy system (He et al., 
1998). Recombinant adenovirus expressing human caveolin-1 was produced by inserting the wild-type human caveoin-1 cDNA into a shuttle plasmid (pAdTRACK-CMV) and performing homologous recombination in $E$. Coli $\mathrm{BJ}$ 5183 with this shuttle vector and a large adenovirus-containing plasmid (pAdEasy-1) following electroporation. Correct recombinants were firstly selected with kanamycin then determined by restriction endonuclease digestion. Infective adenovirus virions were produced following transfection of the linearized recombinant adenovirus plasmid in HEK293 cells. Virus stocks were amplified in HEK293 cells on $15 \mathrm{~cm}$ plates and purified using BD Adeno-X Virus Purification Kits (Clontech, Palo Alto, CA).

\section{Western blot analysis}

Cells were washed with phosphate-buffered saline (PBS), and lysed in ice-cold RIPA buffer (Kim et al., 2006) containing protease inhibitors, $1 \mathrm{mM}$ EDTA, and $0.5 \mathrm{mM} \mathrm{Na}_{3} \mathrm{VO}_{4}$. Cell lysates were centrifuged at $4^{\circ} \mathrm{C}$ for $30 \mathrm{~min}$ at $12,000 \times$ $g$, and supernatant fractions retained for immunoblot analysis. Proteins were separated by $12 \%$ SDS-PAGE, and transferred to PVDF membranes. Membranes were soaked in blocking solution (Tris-Buffered Saline with $0.1 \%$ Tween 20 [TBST] containing 5\% skimmed milk) for $1 \mathrm{~h}$ at room temperature (RT), and probed with primary antibodies at a dilution of 1:200-1:2,000 at $4^{\circ} \mathrm{C}$ overnight. After five washes, membranes were incubated with HRP-conjugated secondary antibodies at a dilution of 1:2,000-1:5,000 for $1 \mathrm{~h}$ at RT. Immunoreactive signals were developed using the SuperSignal substrate (Pierce, Rockford, IL), and detected by exposure to X-ray film (Agfa, Belgium).

\section{Isolation of a detergent-insoluble fraction}

A detergent-insoluble fraction was isolated as described previously, with minor modifications (Kim et al., 2006). Briefly, cells were washed twice with ice-cold PBS, and lysed with HEPES buffer (10 mM sodium HEPES, $\mathrm{pH} 7.5$, $150 \mathrm{mM} \mathrm{NaCl}, 5 \mathrm{mM}$ EDTA, protease inhibitors, $0.5 \mathrm{mM}$ $\mathrm{Na}_{3} \mathrm{VO}_{4}$ ) containing $0.5 \%$ Brij 58 for $30 \mathrm{~min}$ on ice. Cell lysates were centrifuged at $12,000 \times g$ for $30 \mathrm{~min}$ at $4^{\circ} \mathrm{C}$. Supernatants were used as soluble fractions in subsequent experiments. The pellets were washed with $1 \mathrm{ml}$ cold HEPES buffer without detergent, solubilized with lysis buffer $(50 \mathrm{mM}$ Tris- $\mathrm{HCl}$, pH 7.4, 0.1\% SDS, $0.5 \%$ sodium deoxycholate, 1\% Nonidet P-40, 1 mM EDTA, 1 mM EGTA, protease inhibitors, $0.5 \mathrm{mM} \mathrm{Na}_{3} \mathrm{VO}_{4}$ ), and centrifuged at $12,000 \times g$ for $30 \mathrm{~min}$ at $4^{\circ} \mathrm{C}$. These supernatant fractions were insoluble. Individual fractions were analyzed by SDS-PAGE and Western blotting.

\section{Detergent-free discontinuous sucrose gradient ultracentrifugation}

Low-density membrane rafts were isolated using discontinuous sucrose gradient ultracentrifugation, as described previously (Park et al., 2009). Cells were washed, scraped into $0.5 \mathrm{M}$ sodium carbonate ( $\mathrm{pH} 11.0)$, and homogenized using a Dounce homogenizer. The homogenate was adjusted to $40 \%$ sucrose by the addition of $80 \%$ su- crose prepared in MBS (25 mM Mes, pH 6.5, $0.15 \mathrm{M} \mathrm{NaCl}$ ) and placed at the bottom of an ultracentrifuge tube. A $5 \% / 35 \%$ discontinuous sucrose gradient was formed above the sample and centrifuged at $190,000 \mathrm{~g}$ for $20 \mathrm{~h}$ in a SW41 rotor (Beckman Instruments, Fullerton, CA). From the top of each gradient, 1-ml fractions were collected, yielding a total of 10 fractions. Gradient fractions were separated by SDS-PAGE and Western blotting.

\section{Co-immunoprecipitation}

Cell extracts were prepared using modified RIPA buffer (10 $\mathrm{mM} \mathrm{Na}_{2} \mathrm{HPO}_{4}, \mathrm{pH} 7.2,0.1 \%$ SDS, $1 \%$ Nonidet P-40, 0.5\% sodium deoxycholate, $150 \mathrm{mM} \mathrm{NaCl}$, protease inhibitors, 1 $\mathrm{mM}$ EDTA, $0.5 \mathrm{mM} \mathrm{Na}_{3} \mathrm{VO}_{4}$ ) (Choi et al., 2006). Total lysate $(500 \mu \mathrm{g})$ was pre-cleared by incubating with protein A-agarose beads (Biovision Inc. Mountain View, CA) for 3 $\mathrm{h}$ at $4^{\circ} \mathrm{C}$. After centrifugation, cleared lysates were incubated with $1 \mu \mathrm{g}$ of anti-SHP-2 or anti-caveolin-1 antibodies (BD Transduction Laboratories, Lexington, KY) at $4^{\circ} \mathrm{C}$ overnight, and precipitated with protein A-agarose beads (Biovision) for $3 \mathrm{~h}$ at $4^{\circ} \mathrm{C}$. For Western blot analysis, immunoprecipitated proteins were probed with antibody against caveolin-1 and 5\% input proteins were analyzed with anti-caveolin-1, anti-SHP-2 and anti-tubulin antibodies, as described above.

\section{Immunofluorescence assay (IFA)}

IFA was determined as described previously, with minor modifications (Park et al., 2009). Astrocytes cultured on poly-D-lysine-coated coverslips were washed twice with ice-cold PBS and fixed with methanol at $-20^{\circ} \mathrm{C}$. Fixed cells were washed with PBS and blocked with $1 \%$ BSA for 30 min at RT. Cells were incubated with primary antibodies (anti-p-SHP-2, diluted 1:100, and anti-caveolin, diluted $1: 100$ ) overnight at $4^{\circ} \mathrm{C}$, followed by secondary antibodies (Alexa 488-conjugated, diluted 1:600; and Alexa 555-conjugated, diluted 1:500) for $1 \mathrm{~h}$ at RT. Next, cells were washed, mounted in mounting solution (Molecular Probes, Eugene, OR) containing DAPI, and observed under a confocal microscope (Carl Zeiss, Oberkochen, Germany).

\section{Acknowledgements}

This work was supported by the National Research Foundation of Korea (NRF) grant funded by the Korea government (MEST) 2010-0029352, by the Korea Science and Engineering Foundation (KOSEF) through Chronic Inflammatory Disease Research Center Ajou University Grant R13-2003-019 and by the Ewha Womans University Research Grant of 2008 to Y.H.C., and by the National Research Foundation of Korea (NRF) funded by the Korea government (MEST) (2010-0029353) to J.L.K..

\section{References}

Allen JA, Halverson-Tamboli RA, Rasenick MM. Lipid raft microdomains and neurotransmitter signalling. Nat Rev 
Neurosci 2007;8:128-40

Aoki Y, Huang Z, Thomas SS, Bhide PG, Huang I, Moskowitz MA, Reeves SA. Increased susceptibility to ischemia-induced brain damage in transgenic mice overexpressing a dominant negative form of SHP2. Faseb J 2000;14:1965-73

Bennett AM, Hausdorff SF, O'Reilly AM, Freeman RM, Neel BG. Multiple requirements for SHPTP2 in epidermal growth factor-mediated cell cycle progression. Mol Cell Biol 1996; 16:1189-202

Cameron PL, Ruffin JW, Bollag R, Rasmussen H, Cameron RS. Identification of caveolin and caveolin-related proteins in the brain. J Neurosci 1997;17:9520-35

Cao H, Courchesne WE, Mastick CC. A phosphotyrosinedependent protein interaction screen reveals a role for phosphorylation of caveolin-1 on tyrosine 14: recruitment of C-terminal Src kinase. J Biol Chem 2002;277:8771-4

Cao H, Sanguinetti AR, Mastick CC. Oxidative stress activates both $\mathrm{Src}$-kinases and their negative regulator Csk and induces phosphorylation of two targeting proteins for Csk: caveolin-1 and paxillin. Exp Cell Res 2004;294:159-71

Cho KA, Park SC. Caveolin-1 as a prime modulator of aging: a new modality for phenotypic restoration? Mech Ageing Dev 2005;126:105-10

Choi C, Kutsch O, Park J, Zhou T, Seol DW, Benveniste EN. Tumor necrosis factor-related apoptosis-inducing ligand induces caspase-dependent interleukin-8 expression and apoptosis in human astroglioma cells. Mol Cell Biol 2002;22: 724-36

Choi YH, Bernardi R, Pandolfi PP, Benveniste EN. The promyelocytic leukemia protein functions as a negative regulator of IFN-gamma signaling. Proc Natl Acad Sci USA 2006;103:18715-20

Chong ZZ, Lin SH, Kang JQ, Maiese K. The tyrosine phosphatase SHP2 modulates MAP kinase p38 and caspase 1 and 3 to foster neuronal survival. Cell Mol Neurobiol 2003;23:561-78

Couet J, Li S, Okamoto T, Ikezu T, Lisanti MP. Identification of peptide and protein ligands for the caveolin-scaffolding domain. Implications for the interaction of caveolin with caveolae-associated proteins. J Biol Chem 1997;272:6525-33

Gee CE, Mansuy IM. Protein phosphatases and their potential implications in neuroprotective processes. Cell Mol Life Sci 2005;62:1120-30

Godbout R, Bisgrove DA, Shkolny D, Day RS 3rd. Correlation of B-FABP and GFAP expression in malignant glioma. Oncogene 1998;16:1955-62

Gonzalez E, Nagiel A, Lin AJ, Golan DE, Michel T. Small interfering RNA-mediated down-regulation of caveolin-1 differentially modulates signaling pathways in endothelial cells. J Biol Chem 2004;279:40659-69

Gu H, Pratt JC, Burakoff SJ, Neel BG. Cloning of p97/Gab2, the major SHP2-binding protein in hematopoietic cells, reveals a novel pathway for cytokine-induced gene activation. Mol Cell 1998;2:729-40

He X, Goldsmith CM, Marmary Y, Wellner RB, Parlow AF,
Nieman LK, Baum BJ. Systemic action of human growth hormone following adenovirus-mediated gene transfer to rat submandibular glands. Gene Ther 1998;5:537-41

Kim BW, Lee CS, Yi JS, Lee JH, Lee JW, Choo HJ, Jung SY, Kim MS, Lee SW, Lee MS, Yoon G, Ko YG. Lipid raft proteome reveals that oxidative phosphorylation system is associated with the plasma membrane. Expert Rev Proteomics 2010;7: 849-66

$\mathrm{Kim} \mathrm{H}$, Baumann $\mathrm{H}$. Dual signaling role of the protein tyrosine phosphatase SHP-2 in regulating expression of acute-phase plasma proteins by interleukin- 6 cytokine receptors in hepatic cells. Mol Cell Biol 1999;19:5326-38

Kim HY, Park SJ, Joe EH, Jou I. Raft-mediated Src homology 2 domain-containing proteintyrosine phosphatase 2 (SHP-2) regulation in microglia. J Biol Chem 2006;281:11872-8

Kim S, Lee Y, Seo JE, Cho KH, Chung JH. Caveolin-1 increase basal and TGF-beta1-induced expression of type I procollagen through $\mathrm{PI}-3$ kinase/Akt/mTOR pathway in human dermal fibroblasts. Cell Signal 2008;20:1313-9

Lacalle RA, Mira E, Gomez-Mouton C, Jimenez-Baranda S, Martinez AC, Manes S. Specific SHP-2 partitioning in raft domains triggers integrin-mediated signaling via Rho activation. J Cell Biol 2002;157:277-89

Lang DM, Lommel S, Jung M, Ankerhold R, Petrausch B, Laessing $U$, Wiechers MF, Plattner $H$, Stuermer CA. Identification of reggie-1 and reggie-2 as plasmamembraneassociated proteins which cocluster with activated GPIanchored cell adhesion molecules in non-caveolar micropatches in neurons. J Neurobiol 1998;37:502-23

Park JS, Kim HY, Kim HW, Chae GN, Oh HT, Park JY, Shim $\mathrm{H}$, Seo M, Shin EY, Kim EG, Park SC, Kwak SJ. Increased caveolin-1, a cause for the declined adipogenic potential of senescent human mesenchymal stem cells. Mech Ageing Dev 2005;126:551-9

Park SJ, Kim HY, Kim H, Park SM, Joe EH, Jou I, Choi YH. Oxidative stress induces lipid-raft-mediated activation of Src homology 2 domain-containing protein-tyrosine phosphatase 2 in astrocytes. Free Radic Biol Med 2009;46:1694-702

Peng F, Zhang B, Wu D, Ingram AJ, Gao B, Krepinsky JC. TGFbeta-induced RhoA activation and fibronectin production in mesangial cells require caveolae. Am J Physiol Renal Physiol 2008;295:F153-164

Percy CJ, Pat BK, Healy H, Johnson DW, Gobe GC. Phosphorylation of caveolin-1 is anti-apoptotic and promotes cell attachment during oxidative stress of kidney cells. Pathology 2008;40:694-701

Pluskota E, Chen Y, D'Souza SE. Src homology domain 2-containing tyrosine phosphatase 2 associates with intercellular adhesion molecule 1 to regulate cell survival. J Biol Chem 2000;275:30029-36

Razani B, Woodman SE, Lisanti MP. Caveolae: from cell biology to animal physiology. Pharmacol Rev 2002;54: 431-67

Repovic P, Benveniste EN. Prostaglandin E2 is a novel inducer of oncostatin-M expression in macrophages and microglia. J Neurosci 2002;22:5334-43 
Shi ZQ, Lu W, Feng GS. The Shp-2 tyrosine phosphatase has opposite effects in mediating the activation of extracellular signal-regulated and c-Jun NH2-terminal mitogen-activated protein kinases. J Biol Chem 1998;273:4904-8

Suzuki T, Matozaki T, Mizoguchi A, Kasuga M. Localization and subcellular distribution of SH-PTP2, a protein-tyrosine phosphatase with Src homology-2 domains, in rat brain. Biochem Biophys Res Commun 1995;211:950-9

Tang TL, Freeman RM Jr, O'Reilly AM, Neel BG, Sokol SY. The SH2-containing protein-tyrosine phosphatase SH-PTP2 is required upstream of MAP kinase for early Xenopus development. Cell 1995;80:473-83
Volonte D, Zhang K, Lisanti MP, Galbiati F. Expression of caveolin-1 induces premature cellular senescence in primary cultures of murine fibroblasts. Mol Biol Cell 2002;13: 2502-17

Williams TM, Lisanti MP. Caveolin-1 in oncogenic transformation, cancer, and metastasis. Am J Physiol Cell Physiol 2005;288:C494-506

Yamamoto M, Toya Y, Schwencke C, Lisanti MP, Myers MG Jr, Ishikawa Y. Caveolin is an activator of insulin receptor signaling. J Biol Chem 1998;273:26962-8 